\title{
A Novel Approach Towards a Sustainable Ecotourism Community
}

\author{
Mianda Khattab* and Salah El Haggar \\ Environmental Engineering Department, The American University in Cairo, Egypt
}

\begin{abstract}
As tourism industry is one of the main industrial focuses nowadays as it has grown almost by $40 \%$ since 1960 till date and it is expected to represent almost $25 \%$ of the globe's population in 5 years. It has many benefits economically by getting introduced to foreign currencies and better market share; and socially by providing more job opportunities and better lifestyles yet the environmental point of view is not yet a focus, in other words in line with the industry growth huge amount of natural resources are being consumed so as to cover for the needs of the current tourists. Thus there is a need for the introduction of a novel approach that will integrate ecotourism and sustainability by introducing and implementing the zero waste strategy which will ensure conservation of natural resources with safe and environmentally friendly acts, activities and waste full utilization methods following cradle-to-cradle concept as it will be shown in the paper.
\end{abstract}

Keywords: Tourism, Sustainability, Eco-Tourism, Zero Waste Strategy, Cradle-To-Cradle Concept, Sustainable

\section{Introduction}

Tourism industry is counted as a fast growing industry which started in the early 1960 s; it is being improved as time passes by and sustainability acts are being introduced and acted upon. Figure 1 shows a tracking of the number of international tourists; just to show how fast tourism industry has evolved in almost half a century. There was an increase in the level of tourism since the year 1960 till 2008 and a projection for 2020 as indicated by the world tourism organization. Several reasons led to this rise in tourism starting with the fact that it is a new industry being introduced or known of; but also it led to rising the living standards of the community travelled to citizens as well as tourists when taking longer holidays and travelling to distant parts of the world, getting exposed to new cultures and sharing the tourists' own culture. In addition to advances in transport technology for example the jumbo jet allow for relatively inexpensive long-distance travel. All of this raised marketing propaganda to the visited places via Television, movies and social media, etc. leading to a wellfinanced advertising campaigns and thus promoting travelling. (Campus Sustainability, 2015).

* Corresponding author

E-mail: miaz@aucegypt.edu

(C) 2015 International Association for Sharing Knowledge and Sustainability

DOI: $10.5383 /$ swes.7.01.002 


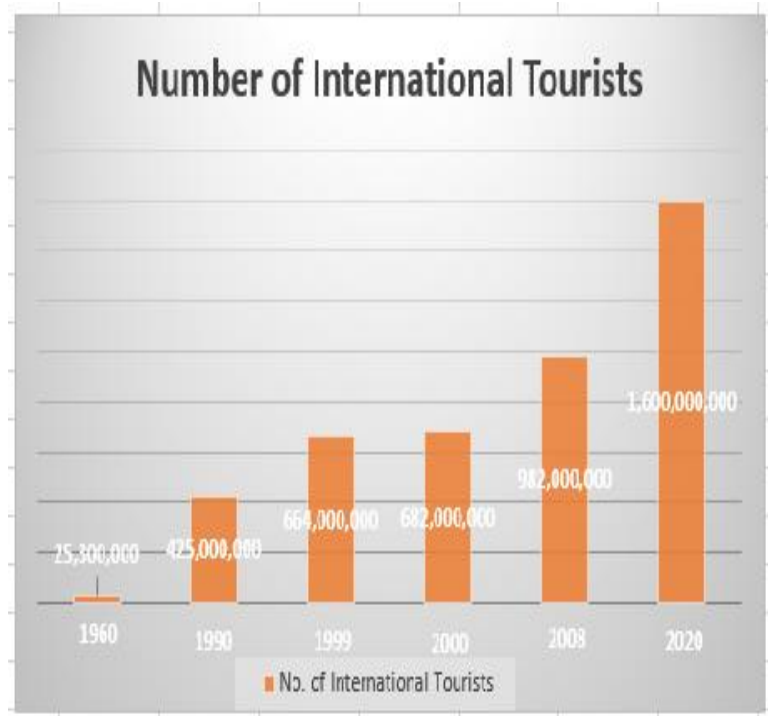

Figure 2: Number of International Tourists as Mentioned by the World Tourism Organization

As shown in Figure 1 that by 2020 the number of international tourists will reach around 1.6 billion, which is almost representing $23 \%$ of the world's population and this shows how fast this industry is growing and in parallel how fast and massive is the consumption of natural resources so as to meet the needed industry growth and this will be seen first in the European countries, then Asian and Pacific then Americas and lastly Africa and Middle East as shown in Figure 2 depending on the number of International tourists arrival in 2013. The impact of that can have the negatives overweighing the positives in the sense that the increase of tourism industry will decrease the level of unemployment and will raise the country's economy with the increase of visiting tourists while spreading the culture and traditions which are focused under social and economic points of view however, the wide immediate, unstudied and unprepared for increase in 50 years as referred to earlier in this paper is leading to massive consumption of natural resources like water, energy and materials which is affecting the environment, being the number one source of tourism existence and reliance and the least of importance to be paid attention at and focused on by each and everyone in the community starting with citizens, government members and even visiting tourists.Tourism industry has so many activities being done within it -- as shown in figure 3, like transportation modes wither by air, cruise or cars, entertainment like theatres, sports arenas, recreational areas and some other facilities like banks, gas station, accommodation, hospitals, real estates, infrastructure and banks which all do require raw materials being usually extracted from the natural resources leading to an imbalance in the ecosystem. So, tourism industry is just like any industry with advantages and disadvantages that is reflecting not only the industry itself; but on the community standards and lifestyle. Some of tourism advantages are flourishing the needs recreation of proper infrastructure (roads, facilities, health care and services) development, as well as being a major source of economy in some countries while generating foreign currency exchange, increasing job opportunities level and thus leading to more destination marketing and attractions.

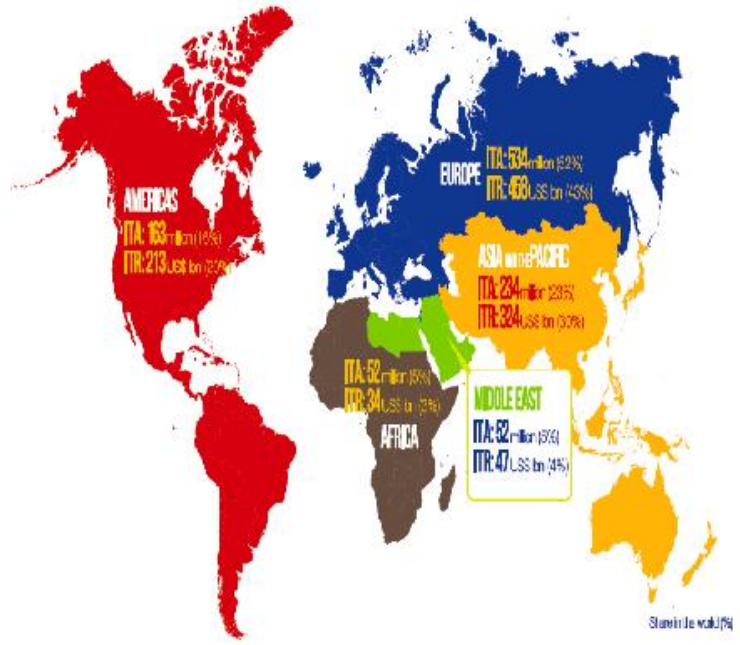

Figure 1: The number of tourists' arrival (UNWTO Tourism Highlights, 2013).

Saying how tourism industry is such a rapidly increasing industry will reflect negatively on the surrounding community and environmental level for instance recreational development can be concentrated like being focused on the touristic areas to perfectly serve the tourists when it is not reaching the local people; same applies to health services and other facilities. Also, the market is unstable and it depends on the USD price in the market. In addition to that, if tourism is not sustainably managed, it can lead to cultural and wildlife destruction; not just that but also tourism industry started affecting marginal employment level like hiring low skilled people with low wage just to cover for the need of employees with the rise of tourism; most of the higher management is outside hiring i.e. different nationality apart from having seasonal employment levels. (Tourism Development, 2015).

Saying this, with such an increase in the tourism industry and abuse of natural resources this will lead to an unbalance in the ecosystem, as the environment will not be able to cope with a rapid increase in high number of tourists in such a short period of time with an unbalance of resources usages. Stating how important tourism industry is and how fast it is flourishing while affecting the surrounding environment with the community social levels and standards, this leads to identifying the need to having a sustainable tourism so as not only to protect the current living and surrounding environment but also ensuring the availability of the needed resources for the future generations as the word sustainable reflects. So, some of the suggested mitigations working towards having a sustainable tourism are avoiding getting involved in environmental depletion acts while raising awareness within the community members and invest in trainings and educational experiences to the hired employees. Also, ensuring that the cultural experience is shared with the tourists so as it adds more community values and checking for more community adding value acts while also focusing on other industries that might be a source of income to back up the drop that might happen from tourism industry and lastly acting in transparency and communication between the government and community members. 


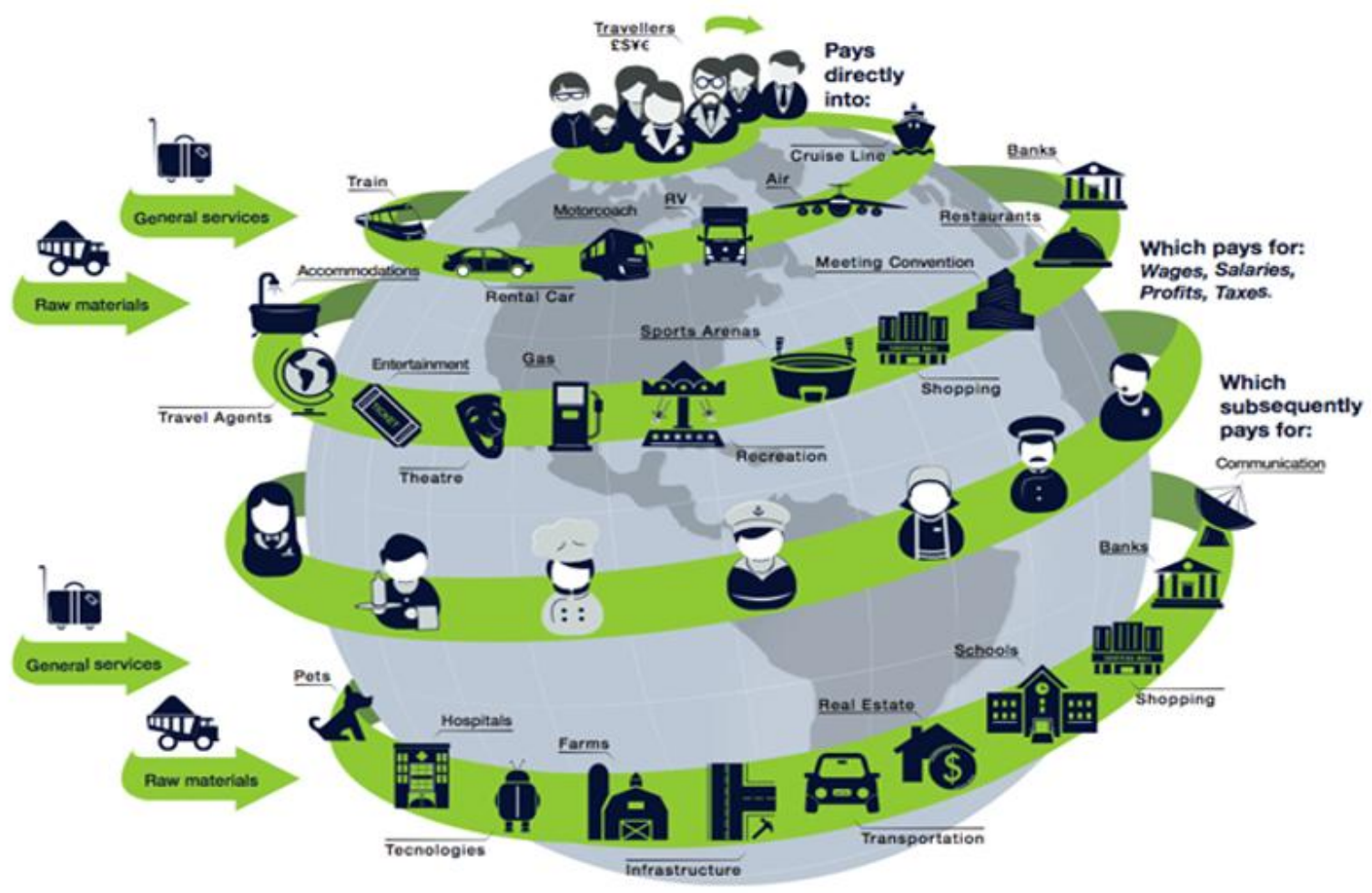

Figure 3: How Money travels within a Touristic Environment (World Travel and Tourism Council, 2015)

But before getting into what is sustainable tourism, types, definitions, how to reach it and what to be done, identifying first tourism stakeholders will assist in identifying who is leading this fast growing industry, what is their future plan and how sustainable are they communicating. Figure 3 shows all of the stakeholders involved in the tourism industry starting with Government, Investors, vendors, NGO's, Infrastructures, hotels and resorts, community citizens, Customers and Tourists, Media with all its types, attractions either natural or religious or infrastructures or places to visit, tour operators and guides and lastly suppliers of food, liquor and forms of entertainment. So in a nut shell, everyone within a community starting with a higher governmental level to local citizens, domestic or international tourists, marketing and media tools, investors either private one hotel investor or a resort investor, either a food supplier or a transportation person, engineers for infrastructure of buildings and transportation roads and bridges engineers all are in a linked chain working either in parallel or preceding one another to finish a job that mainly depends on a proper image and marketing.

Tourism sustainability is a complex system that is connected with the social systems, the environmental access of resources and the ecology through the touristic activities and acts being done. Tourism is one of the largest industries that lie on services and productions giving a high economy return back on share. (Fennell, 1999)

As much as it sounds impressive to find all of these community members working together and in line so as to deliver a specific representable and attractive image for the tourism industry in each, so as to attract more tourists; as much as it reflects a huge concern of communication methods between different community levels like government and local citizens of different backgrounds, economical standards and intentions. In addition to that this sizes the previously mentioned tourism industry environmental problem and concern about abusing the environment and natural resources; so having a common established ground of definitions about the environment, environmental impacts not only to the surrounding nature but to the local citizens lifestyle and future generations as well as the long term negative effective on the country's economy when all of its resources are abused and there is no other replacement for further touristic attractions.

It is very critical that all of these members have defined international guidelines for a properly established and ethically managed touristic industry which focuses on the 3 pillars of sustainability known as economic, social and environment (which is the least point of focus amongst stakeholders and tourists) so as to reach the desired outcome of having a better environment, lifestyle and a safely guaranteed availability of resources for the future generations out of this entertaining and economy generating industry.

The tourism industry is consuming a massive amount of natural resources that is why integrating the conservation of resources (water, energy \& materials) is needed nowadays specially with this growing industry. Thus the objective refers to the need for integrating sustainability with eco-tourism applying the zero waste strategy. This novel approach aims at establishing a common ground of the guidelines on the conservation of natural resources and saving the environment while achieving the needed success and economic level aimed for by such a growing industry like tourism. 


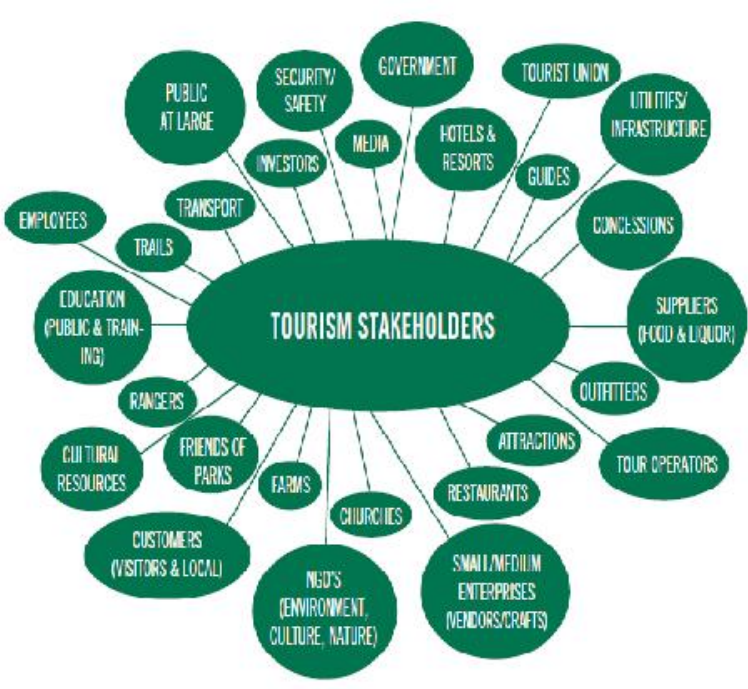

Figure 3: Stakeholders in the Tourism Industry. (Eileen, Et Al. 2005)

Tourism Types and Definitions:(Sustainable Tourism, 2014)

Before getting more into sustainable tourism approach, some definitions about tourism industry needs to be identified so as to have a clear study of the available tourism types and design the proper methodology for reaching the needed sustainable tourism community.

\section{Tourism:}

Defined as the activity of travelling or visiting other places either internationally or nationally either for work, study or leisure. It aims at promoting other places to visit and see while encouraging different cultural activities and inputs with the enhancement of economic standards for the travelled-to country.

\section{Geo-Tourism:}

Geo-Tourism is defined by the National Geographic as synonym to sustainable Tourism however it reflects more on the location geography and it aims at promoting the place by "the sense of the place" rather than the touristic and industrial efforts.

National Geographic defined geo-tourism as "Tourism that sustains or enhances the geographical character of a place its environment, heritage, aesthetics, culture, and the wellbeing of its residents. Geo-tourism is sustainable tourism energized. It sustains, but it can also enhance-by means of restorative and constructive forms of tourism that fit the nature of the destination" (National-Geographic, 2008-2010)

\section{Responsible Tourism:}

Responsible tourism is defining tourism as an Industry that consumes the resources in a more responsible way and thus generating a bigger economic benefit. Not only that but it also shows the cultural sensitivity responsibility by the respect of hosts and tourists to the place they are visiting in terms of its natural resources reservations in line with cultural and traditional acts.

\section{Sustainable Tourism:}

Defined as a continuous process involving all stakeholders participation for a continual monitoring that works towards improving/ introducing new corrective methods whenever is needed so as to reach a sustainable tourism.

- UNWTO defined Sustainable Tourism as the act of "meeting the needs of the present and the host regions while protecting and enhancing opportunities for the future. It is defined as a leading to management of all resources in such a way that is economic, social and aesthetic needs can be fulfilled while maintain cultural integrity, essential ecological processes, biological diversity and life support systems" (UNWTO, 1998) (Atamhenwan, 2015).

- UNWTO defined sustainable Tourism in 2005 as "the tourism that takes full account of its current and future economic, social and environmental impacts, addressing the needs of visitors, the industry, the environment and host communities". (UNWTO, 2005) (Atamhenwan, 2015)

- Weaver defined sustainable tourism as the "wise usage and conservation of resources in order to ensure their long term viability; it involves the maximization of the positive impacts of tourism and the minimization of the negative impacts at the same time" (Weaver, 2006) (Atamhenwan, 2015)

- Stoddard et al defined sustainable tourism as "a developing tourism industry in such a way that the natural environment is protected and local cultures are preserved, for the benefit of the present and future generations of host communities and tourists, as well as tourism businesses" (Stoddard et al, 2008) (Atamhenwan, 2015)

- Goeldner and Ritchie defined sustainable tourism as "a development that creates a balance by providing high quality experiences for visitors and maximizing the benefits of tourism for stakeholders in a destination, without compromising the social, environmental and cultural integrity of the destination" (Goeldner and Ritchie, 2008) (Atamhenwan, 2015)

Aims at promoting sustainability acts and practices by it will reflect on the respect and responsibility towards the sociocultural reality and this will lead to an increase the level of touristic satisfaction. It is more concerned about economic community level as a first focus which will be based on a better environment as a second supporting focus. Figure 4 shows the evolution of sustainable tourism and the forms of tourism which started by discrepancies leading to disrespect of the sustainable development principals within a form of tourism, to the move of slight integration between sustainable tourism and forms of tourism sustainable development principals till reaching the ideal expected situation where sustainable tourism and the sustainable development forms of tourism meets and integrate. 


\section{Eco-Tourism:}

Eco-tourism is defined under a form of sustainable tourism and it aims at promoting the lower level visited areas with undistributed natural resources. It is more concerned about the environmental acts and activities regardless of their economic effect. Ecotourism Society defined Ecotourism as "a responsible travel to natural areas that conserve the natural environment and improve the living standards of local people" (Ecotourism Society, $1991 \mathrm{a}, \mathrm{b})$ (CHEIA, 2013)

Ecotourism Association of Australia defined Ecotourism as "Ecologically sustainable tourism that is protecting the natural environment and encourage understanding, appreciation and conservation of cultural elements" (Ecotourism Association of Australia, 1992) (CHEIA, 2013)

Ross and Wall defined Ecotourism as "strategy for preserving natural areas while promoting sustainable development of the area" as shown in figure 5 where ecotourism is defined as the protection of natural resources as a primary focus which will then generate revenue, include local involvement and spreading environmental education that will lead to conservation of natural resources in line with economic development which all refills back in sustainable acts. (Ross and Wall, 1999) (CHEIA, 2013)

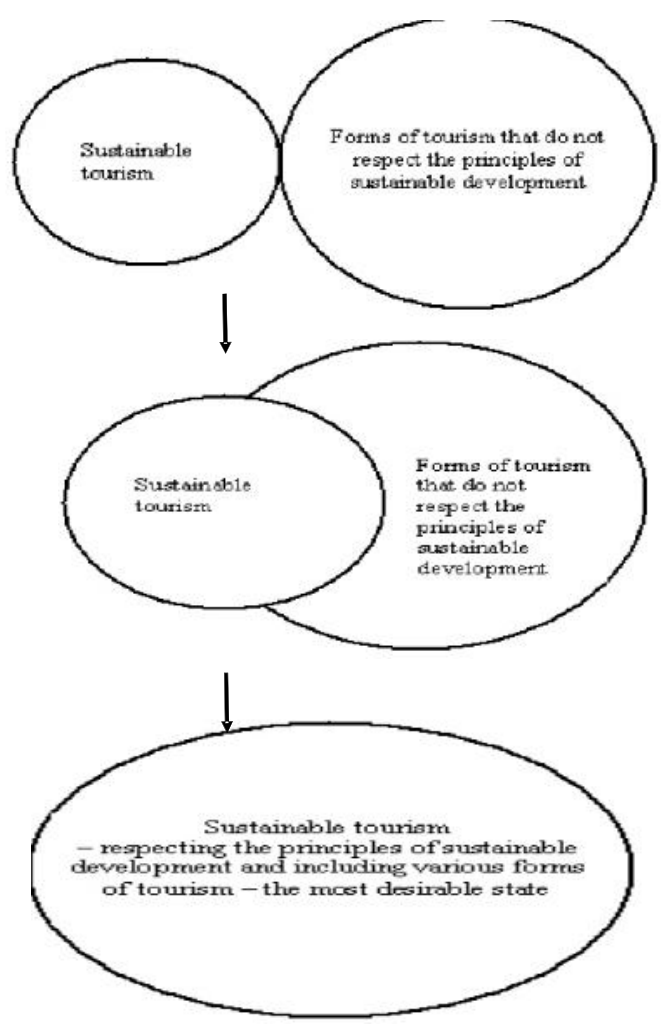

Figure 4: The Evolution of Sustainable Tourism and various Tourism forms (Butowski, 2012)

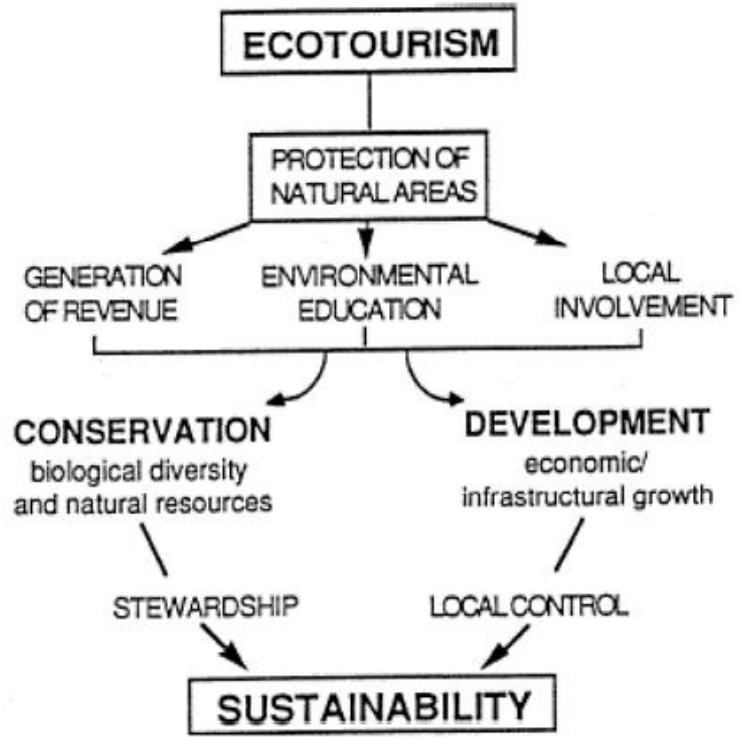

Figure 5: Perspective of Ecotourism (Roll, Wall, 1999) (CHEIA, 2013)

All of these tourism terminologies is mainly identifying the type of travelling tourist as well as being an improvement from a generic word like tourism to a more specific commonly known vocabulary; most of the newly introduced terminologies should be driving to green travel, where the tourist is aware of his acts and is acting responsibly according to the environment. Green Travel While moving to studying the urge for having a green travel which might be reached through sustainable tourism, one should first study touristic attractions which attracts international tourists and makes them favor one place to another, facilities, transportation, actives or accommodation and ecotourism of the place or its sustainable level as stated in some sources are considered to be the most important reasons to privilege one place to travel to rather than the other place and on the other hand when these attractions are maintained while meeting the tourists' needs and serving the environment thus they will help in achieving the sustainable touristic goal. These attractions can be ideographic depending on how unique the place is, or organizational depending on the size of the attractions that this place occupies or cognitive relying on the feelings that a tourists gets upon visiting and being in that place. (Fennell, 1999)

As there is a wide variety of definitions that are being introduced under tourism industry which are mentioned by different authors under different levels of understanding; this refers back to the need to establish a common ground of common definition and guidelines on the conservation of natural resources and saving the environment while achieving the needed success and economic level aimed for by such a growing industry like tourism, the new definition will be identified later in this paper as Sustainable Ecotourism applying the Zero Waste Strategy in order to conserve the natural resources.

Ecotourism and Sustainable Tourism:

Ecotourism and Sustainable tourism are the new terms being used in the tourism industry for a decade where some hotels, 
resorts and destinations claim to be environmentally friendly by using either of the previously mentioned words. However both words are not the same, they are related to the same objective of efficiently and effectively using the available natural resources without abusing the environment or affecting the availability of these unrecovered natural resources to the future generations.

Ecotourism is an old concern since 1990 linking between responsible tourism and how would it be said to be "Green" as well as it is considered to be a sustainable development tool as it is considered to benefit local people, spread the needed sustainability needed information to its visitors through awareness and conserve natural resources. Till 1991 when the International Ecotourism Society (TIES) introduced the first official definition to ecotourism to be a set of principals defined as "Ecotourism is responsible travel to natural area that conserves the environment and sustains the wellbeing of local people" while afterwards the International Union for Conservation of Nature (IUCN) defined ecotourism as "An Environmentally responsible travel and visitation to relatively undistributed natural areas, in order to enjoy and appreciate nature (and any accompanying cultural features- both past and present) that promotes conservation, has low negative visitor impact, and provides for beneficially active socio-economic involvement of local population". (Wood, 2002)

While ecotourism has begun as an idea of interest as further research has been taken in 1970 in Kenya to test the advantages of the economic wildlife tourism focusing on hunting animals and it led to banning this activity in 1977. Some biologists followed the ecotourism benefits on their areas of focus like rain forests, corals reefs and biological diversity studies in 1980s and this helped in launching specifications for scientists about remote zones through small businesses. In parallel there was an increase in the outdoor and environmental travel for camping and hiking by touristic companies who have introduced local groups named as (Conservation Groups) in the visited places of by raising funds for a cause. Accordingly these companies have argues that they have started ecotourism since long time ago by actions until the term Ecotourism was introduced and used by the business travelers and governments to promote the visiting areas. However, they were lacking the major focus of ecotourism principles known to include contribution for biodiversity conservation while sustaining the wellbeing of inhabitants, no environmental abuse by minimizing any nature environmental impacts and including educational and learning experiences sessions about conservation and ecotourism. Also, directing any revenues to be used for the natural areas conservation and rely on using the already built infrastructure which are going in harmony with the culture and nature. (Wood, 2002)

In 1997, the Association for Ecological Tourism in Europe established environmentally friendly oriented tour operations that led to the development of ecotourism guidelines and till date, ecotourism has many different meanings and synonyms like geo-tourism and pro-poor tourism which is benefiting the poor people in the society; yet no matter what definition synonyms ecotourism might have, they all share and aim towards the same objective of

conserving the environment while raising sustainability awareness in between the tourists (Wood, 2002).

Figure (3) below shows where Ecotourism lies within tourism sustainable forms as well as how ecotourism is mainly a primary from Nature tourism (which is based on natural scenery) and the part of rural tourism (which depends on rural travels) and other from cultural tourism (which is more focused about the culture). So ecotourism is a form of sustainable tourism acts, the major difference is that ecotourism is primarily aiming at saving the environment as the first objective while sustainable tourism is aiming at focusing on the economic return by saving the environment and this is to have a balance ecosystem as defined in the three known sustainability pillars economic, environment and social.

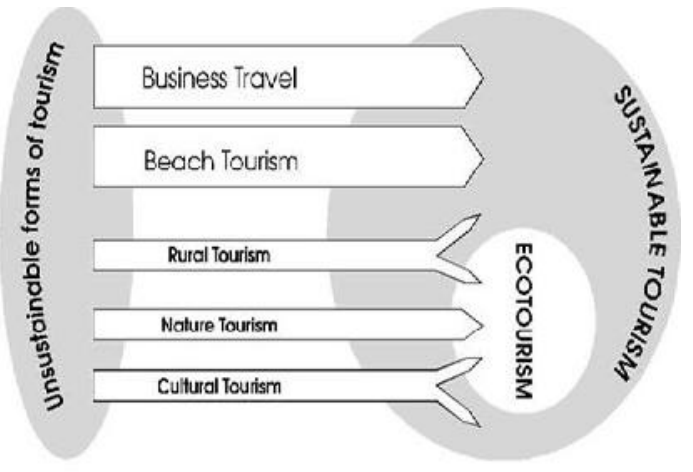

Figure 6: Ecotourism as a Sustainable Development Concept (United Nations Environment Programme, 2015)

\section{Ecotourism Requirements:}

Six principals are being introduced by the International Ecotourism society (TES) that are used as guidelines for ecotourism community implementation. These principals include eliminating negative impacts on the nature, ensuring that local citizens provide positive experiences for the tourists, providing benefits to local people like economical and job opportunities, focusing on proper awareness to locals and educating tourists as well, revenues are to be spent on conserving the environment and lastly raising political, social and environmental standards with host countries (The International Ecotourism Society, 2013).

These six principals are focused more about social and economic points with less focus and contribution to the environmental conservation and focus. In addition to that, the previously mentioned principals do not state clearly on how to apply each principals while taking into consideration different cultures or communities' different approaches.

\section{Ecotourism Certification:}

As certifications are considered to be the guidelines to regulate the operations within an industry like tourism industry while setting succeeding in achieving previously identified guidelines that usually address quality, social operations and environmental concerns. The certifications are considered to be the role of governments and NGOs to identify and present to the industries to abide to; so as most of the governmental concerns are tending towards sustainability and as the aim of NGOs is to guide towards a better tomorrow which is sustainability in other words thus most of the identified certifications within the tourism industry are focused on that (World Tourism Organisation, 2003)

As Ecotourism is mentioned before to be a growing industry on an international level having to meet several demands that are summarized under social and environmental safety while adhering to several standards like raising cultural awareness, providing a positive and real experience and learning phase to 
visitors and inhabitants and financial or economic return back to the community as well as a stronger political standard. Thus to maintain the needed and appreciated results for Ecotourism while guiding to more sustainable acts, Ecotourism needs to be certified (Butsam, 2012).Ecotourism being certified will assist the shareholders, citizens and visiting tourists in several ways. Apart from being a recognizable eco- certified place to promote or travel to, the certification also has the advantage for shareholders of being able to access new technology financing as well any sustainable acts financial funding needs. While for citizens and tourists, just ensuring that the place being visited is conserving the environment while guaranteeing a healthier and more prosperous journey that starts with awareness and goes through an educational memorable experience (Butsam, 2012)

\section{Ecotourism Certificates:}

Ecotourism certification started to take place in the early 2000s ever since the population started to massively increase and the natural resources are being depleted at a high rate leading to a wider increase in the gap between the rich and the poor while increasing the level of societal insecurities and rise in criminal levels.

\section{International Mohonk Agreement:}

Ecotourism certification started with the International Mohonk Agreement issued in 2000 which introduced and identified the principals of ecotourism and sustainable tourism certification. It linked sustainable tourism with ecotourism stating that it is the type of tourism minimizing social and economic impacts on the surrounding environment while having a better economic advantage coming back to the local community (Klintman, 2012).

\section{Certification for Sustainable Tourism (CST)- Costa} Rica:

CST is a certificate that is designed for the business sectors to differentiation the tourism sectors businesses based on their activity compliance with the nature, social and cultural managing of resources (Sustainable Tourism, 2014).

\section{EarthCheck Certification:}

Said to be the World's leading scientific benchmarking certification and tourism and travel advising group. EarthCheck provides consulting guidance and services to governments, destinations and businesses ensuring the delivery of a safe, environmentally friendly and clean destination tourism area (EarthCheck, 2015).

4. Sustainable Tourism Eco-Certification Program (STEP):

STEP is designed by the tourism industry in Colombia based on an environmental framework that studies sustainable acts within the touristic businesses while also being an assessment educational tool (Ecolabel Index, 2015).

5. Green Key Program in Mexico:

A program that has started in Mexico in 2008 introducing Ecotouristic acts and ideas for tourists and tourism industry to act green and be green (Sustainable Tourism, 2014).

\section{ECOTEL Certification:}

ECOTEL is a certificate designed for hotels/resorts sustainability that was issued in 1994 yet it was just focused on social responsibility and pollution prevention. However now it is recognized for full sustainability acts. The certificate evaluates the hotels based on how they manage the wastes, energy consumption, water usage and management, environmental footprint and how much sustainable education is being taught to the employees and community through awareness and acts (HVS SUSTAINABILITY, 2015).

The above ecotourism certification has helped in identifying the responsible acts that should be done by operators and visitors so as to earn the certification. From which the place has gained an advantage for being known as an Ecotouristic Certified place which will change any negative impacts being created by visitors or inhabitants leading to creating a sustainably developed Ecotouristic place (Butsam, 2012).

The problem is addressed through certifications which propose solutions however too many certifications concerning sustainable tourism are introduced and this leads to confusion to tourists on what is the need and difference between all of these certifications, which to follow, which is more known, which has the better pay-back period and benefits. A lot of certifications being introduced, more confusion is being caused and loss of certification credibility is reached. In addition to that, most of the hotels and resorts tend to apply sometimes for any certification under the words "environmentally friends, sustainable or eco-industry" so as to use it as a marketing attraction to tourists however, they may not choose a certification that is really working towards the previously mentioned keywords in line with applying only once for such certification without any challenge to further enhance the hotel or resort facilities, services, activities and acts so as to renew the certification or apply for a higher graded one.

This refers back to the need to integrate ecotourism with sustainability applying zero waste strategy and this is to ensure natural resources conservation.

\section{Eco-Tourism \& Sustainability:}

Ecotourism as defined as a form of Sustainable Tourism aiming at protecting the environment as well as building a strong economic $\log$ for a country while working towards a more developed community by contributing to biodiversity conservation, responsible actions from tourists and local communists to save the environment as well as promoting sustainability while ensuring an unforgettable learning experience. Ecotourism is working towards sustainable development which is known to be conserving or efficiently using the current resources to meet the current needs without affecting the availability of resources for the future generations. As much as this concept is getting clear to many developing and developed countries, as much as it is getting harder to be implemented as the gap between the rich and the poor is increasing within the community and different communities. And this is due to unethical acts by not offering job opportunities to the public or even teaching them to fit a job requirement, by pretending to act sustainably and gain more money in return yet not spending this money back on the community and by poor communication between community members and government members. As shown in figure 4 below that ecotourism development is part of sustainable development only when the points of social, economic and environment, which are the 3 pillars of sustainability, are being fulfilled.

As for social commitment the local culture should be maintained and promoted for through events and festivals, infrastructure should be modified to reflect the culture as this will be a major aspect to differentiate between one country and 
other is the different culture representation. Also the life style of communists and their attitudes towards the surrounding environment and with the tourists will reflect on the mind set and comfort level of citizens within the community.

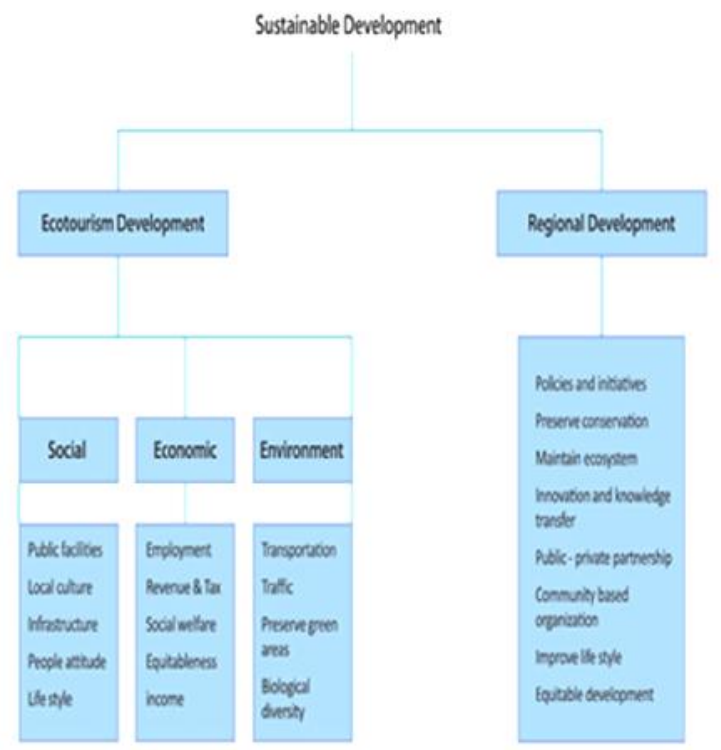

Figure 7: Ecotourism and Sustainable Development (Kiper, 2013)

On the other hand, economic standard is a major aspect to governments and local communists as per the taxes collected and income gained from ecotourism should be reflected back on enhancing the community lifestyle and living standards as well as providing more job opportunities to the public. Lastly the environmental commitment is to preserve the green areas, biodiversity and wildlife as well as offering services and transportation modes that don't harm back the environment.

\section{Is Ecotourism Really Sustainable?}

Ecotourism is working towards sustainability and sustainable development as described in the previous sections. More countries are working hard to be names as an Ecotourism destination and earn the corresponding certification however, this is mostly aimed for having higher economic earnings by both businesses and hotels. So is ecotourism really sustainable? The answer is No. Nothing is perfectly done, and ecotourism is rather a new terminology being introduced into the touristic market in different format however it is mainly a buzz word for marketing a place rather than a word for action to save the surrounding area in the first place. Most, if not all, of the touristic areas that are claiming or working towards being Ecotouristic are implementing some of the needed actions to earn it like introducing new hotel regulations to conserve the environment, offering job opportunities, raising awareness and offering promotions however how do they protect the wildlife for instance, who is monitoring the Ecotouristic sustainable acts and measuring its performance or success so far? Is there any hotel/resort reporting a quality check for the achievement or maintaining the properly needed environmental level? What do the hotels/resorts do after earning the certification, do they work harder for another environmental certification or enhancing the number of points earned and the corresponding award level for instance moving from silver to gold to platinum award or do they just stop at earning the certification and raising marketing awareness about it for as long as they live?
How long is the wildlife protected when claiming sustainable actions versus its protection when regular actions are being implemented? Is the difference worth it? The difference in understanding about ecotourism and sustainable actions from one person to another, from one community to another, how does that affect globally? All of these questions are left unanswered.

Policies and practices should be modified in order to fit for Ecotouristic global definitions and actions as most of the ecotourism activities are not being done exactly as stated by the specified and characteristics forming a universal cure it is rather fixing somewhere on the globe and causing environmental disturbance somewhere else where there is no proper environmental acts or follow up. Thus there should be much more follow up, more global awareness as per global standards implementing plans for development and natural resources conservation that does really ensure environmental and ecological integrity while providing the needed ecotourism experience (Kiper, 2013).

As ecotourism is a responsible act towards the environment and it has advantages when being professionally, ethically and responsibly applied as it is currently negatively affecting the environment. First of all the kind of marketing being done on a destination is aiming for just touristic economy and losing sight on other industries that might need investment to be another source of income, so what will happen if this country's touristic destinations are no longer number 1 , wont it economically drop? Will it be too late to focus on another industry source of income? Won't it cause instability when a global economy issue occurs like a drop in the dollar's value? It will definitely affect all of the market however it shouldn't just be a single source of focus of international income.

Apart from economic point of view, converting landscapes to be a profitable land is a good point of view when the land is efficiently used as per the only needed space but not over estimated or over compromised land, in some cases residents might be asked to leave to another area as the one they are living on is counted as a natural landscape for instance. If the government didn't compensate these residents to live somewhere else, this will lead to an unbalance in the community lifestyle. Also, ecotourism could be widening the gap between the rich and the poor as it is aimed for high class people who can actually afford such travel expenses. So what happens is that these people are investing money in another country and being a reason for more job opportunities in these other countries however, these expenses are not being reflected back at their own country nor are they investing even in the form of taxes on their community by such travels so the gap between the rich and the poor is widened (Disadvantages of Ecotoruism, 1999-2005).

\section{Zero Waste Strategy and Eco-Tourism:}

As touristic villages are part of the community aiming towards enhancing the environment as it is counted as the main resource behind tourists attraction, it also leads to an increase in the economy while providing more job opportunities as it gets into more sustainable actions as illustrated in figure 5 for instance and as a result it will positively and sustainably pay back to the community as it is committed. A successful and sustainable touristic village shall be designed in a closed loop structure to eliminate the waste and pollution while using the available resources efficiently. 
Having unequal and inefficient natural resources distribution leading to an imbalance in the ecosystem and negatively affecting the lifestyle of the current citizens; this raises the concern of working towards having sustainable acts to reach a sustainably balanced community and ecosystem starting with the most popular and dependent activities which is the Tourism Industry. Sustainable acts has different forms of actions within the Tourism Industry as discussed earlier like studying the ecotourism, sustainable tourism, sustainable development within tourism industry all of which are working towards managing the natural resources so that no gap in resources, deficiency in meeting the needs or widening the gap between rich and poor while increasing criminal and insecurity level within a community occurs. One of the new sustainability generated concepts is "zero waste" which is referring to studying the use of resources for long term efficiency. Zero waste can be achieved efficiently while following the Cradle to Cradle approach discussed below.

The strategy behind the touristic villages is to follow cradle-tocradle approach. As shown in figure 6 it is a close loop starting with the raw materials extraction from earth (cradle) till it is returned back sustainably to earth following a safe utilization process. This process starts with raw materials extraction going through the needed processing and manufacturing of materials then packaging to be transported to the corresponding factories or stores then used in homes and then the wastes are divided into recyclable or reusable wastes and disposable ones. The wastes are collected and sent to a transfer station which will check for the needed recycling ones to be done on-site else if any recyclable material cannot be done on-site then it will be sent to an off-site recycling. And this is to ensure to optimum and most efficient use of resources and reusing of products.

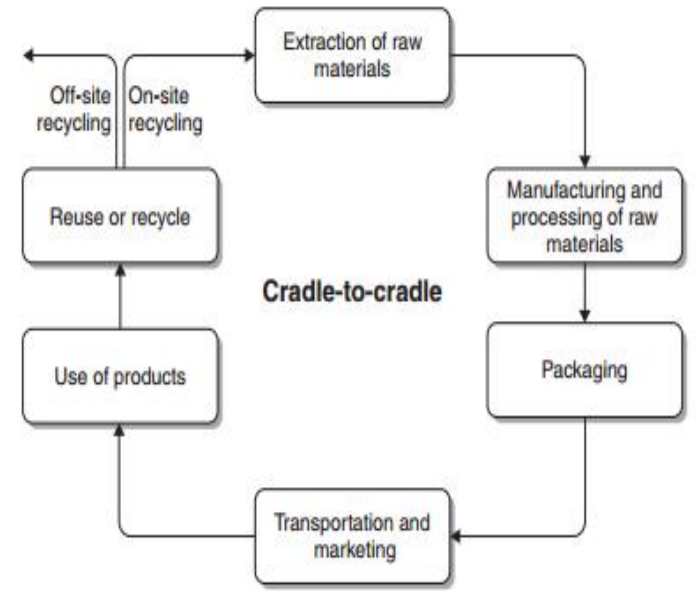

Figure 8: Cradle to Cradle Approach (El-Haggar, 2007)

As a method of testing and evaluating the environmental activities associated with any industry including tourism, a Life Cycle Assessment (LCA) has been developed based on the Cradle-to-Cradle approach. LCA is a tool that will assist in identifying all of the environmental effects resulting from the activity of raw materials usage, waste generation, going through processing all the way to recycling. The LCA encompasses the $7 \mathrm{R}$ golden rules which are regulations which is the introduction of laws that will enforce environmental raw materials usage and waste utilization, reduce the raw materials used starting from the source, reuse the produced products in the same usage or a different one, recover energy from the disposed wastes, recycle wastes, renovate the ongoing traditional waste management processes and rethink. Those rules being encompassed within the LCA ensure that the process is environmentally friendly and is aiming towards a minimal pollution level environment that could be claimed to be a zero waste environment. (El-Haggar, 2007), Sustainable Industrial Design and Waste Management, 2007.

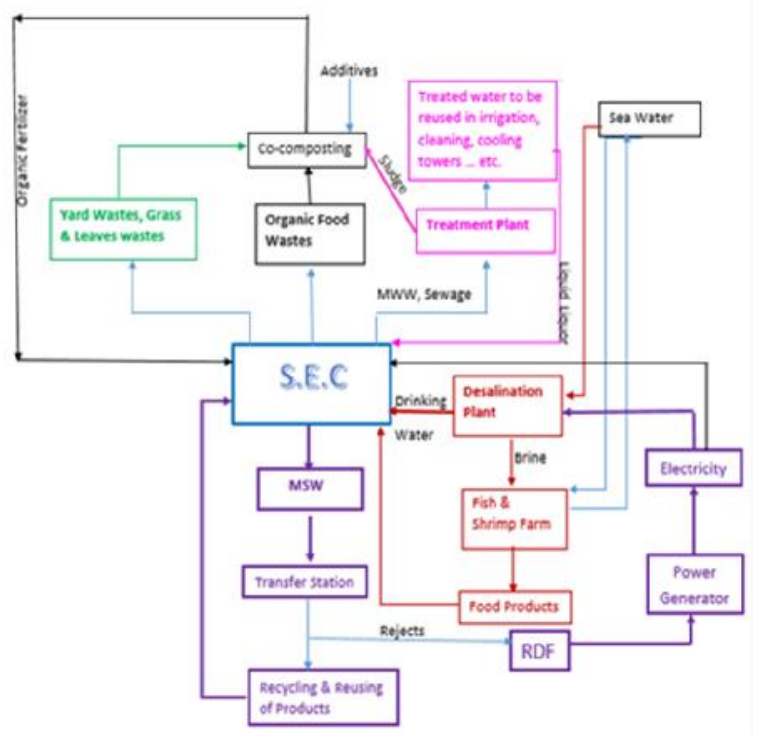

Figure 9: Sustainable Zero Waste Ecotourism Flowchart

Sustainable Zero-Waste Ecotourism:

Figure 10 shows the flowchart for a sustainable zero waste ecotourism which is aiming for zero waste where there is a closed loop since the start of materials extraction from nature to be used as services or products till they are recycled, reused or environmentally utilized in the environment. And this will lead to minimizing the level of natural resources extraction while safely and environmentally recycling or reusing them and thus preserving the environment. This kind of act will lead to a sustainable community by saving the current irreplaceable natural resources and consequently ensuring the presence of natural resources to the upcoming generations. Lastly for Ecotourism as this flow chart is applied on a touristic resort which has all kinds of activities like entertainment, hosting, catering, transportation, amusement parks, recreational areas,... etc. so now the

Ecotouristic area is aiming for saving the environment and natural resources first which is the main reason and attraction behind the establishment of this touristic area and secondly comes the economic payback or benefit.This newly introduced concept of sustainability is aiming for environmental acts, economic benefits and better social standards in which more job opportunities will be available by the introduction of processes and manufacturing facilities to have several closed loops within the overall community close loop. Thus better lifestyles, lower level of unemployment and enhancing educational levels in which these employed community members will be introduced to trainings and leaning programs so as to have strong languages to communicate with tourists as well as the expected sustainable acts and modes of working that they shall follow so as to leave a positive impression and feedback to tourists. Saying that, there will be better awareness within the community and more marketing modes and tools so as to apply the needed for promoting environmentally friendly acts and services. 
The flowchart introduces a cradle-to-cradle zero waste strategy model for a sustainable ecotourism community (S.E.C) which as shown in figure 10 has an on-site desalination plant. A desalination plant is a facility built on-site for the hotels or resorts have lack of fresh water availability and where also having pipelines that can transfer fresh water from a nearby site is costly; therefore a desalination plant is constructed on-site so as to process sea water and produce fresh and drinkable water. As it is known that sea water is high in salinity so the salt being produced from the desalination process will be used in fish \& shrimp farms where additional sea water will be added to these marine lives which are living on high salinity sea water and they can be used as food products in S.E.C. And therefore having a closed loop for sea and drinking water from S.E.C. and back to S.E.C. Also, S.E.C produces municipal solid wastes (MSW) which are defined to be the daily wastes; being divided in figure 10 as non-organic MSW and Organic food wastes. All of the wastes are collected from the S.E.C. where the non-organic MSW are being sent into a transfer station which is defined as waste management sites allowing for safe waste utilization systems unlike landfills. The collection trucks transfer/unload the wastes from a location to them. In a transfer station facility the wastes are further separated and larger trucks can send the segregated wastes into recycling facilities as shown in figure 10 that the recyclables or products and materials that can be reused are being transferred to their facility of specialty and after being recycled or modified for reusing; the products such as coat hangers and waste plastic bags are resent back to the S.E.C. and this aims at environmentally reusing the generated wastes (by recycling or reusing) also minimizing the amount of natural resources needed to produce new products and this all leads back to another closed loop of MSW from and to S.E.C. Lastly, out of some non-recyclable or non-reusable MSW like wood, plastics and paper for instance can be used in the production of Refused Derive Fuel (RDF) which is briefly an environmentally friendly low toxicity and high energy fuel recovered from wastes and it can be used as an energy source to run the machines in the desalination plant and returned back in the form of electricity to the S.E.C. and thus reducing the need of diesel or natural gases driven machinery in line to reducing the amount of energy being consumed in a process and thus ensuring a cleaner and healthier environment.

Municipal Liquor wastes, also known as sewage wastes are another type of wastes being produced in the S.E.C. This type of waste will be treated by sewage treatment processes to produce sludge and effluent or safe reusable water. The effluent can be used in irrigation systems, cleaning modes or for the AC's cooling towers while the sludge will be mixed with other organic waste for a co-composting process as described in the paragraph below.

The organic food wastes in line with yard wastes, grass and leaves wastes will undergo a co-composting which is aerobic waste decomposition process where the waste is stacked in piles for fermentation using the sludge produced from the municipal liquor wastes (sewage wastes) loop discussed above in addition to some additives like rock phosphate, potassium,..etc. which are to be added to adjust the desired output from the co-composting stage which are organic fertilizers that will be added on the golf land or green areas within the S.E.C so as to increase its fertility and this will be the forth closed loop within the S.E.C community.

The sustainable zero waste ecotourism community novel approach discussed is designed to serve the community for a healthier, safer and pollution less environment by applying cradle-to-cradle approach in all of the available waste production types and thus ensuring zero waste strategy is being applied. In other words, ensuring that the produced output wastes are being used as input products within S.E.C.

\section{Conclusion}

Tourism is counted to be the primary source of living for most of the developed and developing countries due to the benefits it brings along from the economical side and social perspective. Yet it was thought by some shareholders that the natural resources are present in infinite amounts and thus giving themselves the right to consume as much as they want even in an unplanned manner of resources usage leading to an imbalance in the ecosystem. With the introduction of sustainability in 1992 shareholders started to reconsider their daily activities within a touristic community however, since sustainability and ecotourism are new concepts having millions of authors, writers, public figures and community concepts that all lead to a misleading or a vague concept and guidance. Thus there was a need to integrate the common practice of ecotourism with sustainability with ecotourism in a novel approach of using a zero waste strategy to have a fully environmentally friendly Sustainable Ecotouristic Community from the beginning of raw materials extraction from the nature going through environmental processing/ treatment and usages till safe/ environmental waste utilization, reusing or recycling of products. This is all tending to conserve the environment and the natural areas and resources ensuring that there will be no deficiency in natural resources for the upcoming generations

\section{References}

[1] Alexander Leicht. (2015). Education for Sustainable Development at UNESCO.

[2] APIRA CONFERENCE- The Paradox of Sustainability Definitions. (2010).

[3] Atamhenwan, E. (2015). What is Sustainable Tourism? (Possibility and impossibility of sustainable tourism).

[4] Butowski, L. (2012). Sustainable Tourism- A Model Approach. INTECH. Retrieved from http://cdn.intechopen.com/pdfs-wm/35517.pdf

[5] Butsam. (2012, May 14). The Role of certification in international ecotourism operators' internet promotion of education. Jouranl of Ecotourism, 11(2), 85-101. Retrieved from

http://www.tandfonline.com/doi/abs/10.1080/14724049.20 12.683005? journalCode=reco20\#.VeFo-fmqqkp

[6] Campus Sustainability. (2015). Promoting Sustainable Tourism. Retrieved from https://www.iso.cuhk.edu.hk/english/publications/sustainab le-campus/article.aspx?articleid=61077

[7] CHEIA, G. (2013). Ecotourism: Definition and Concepts. Journal of Tourism(15). 
[8] Disadvantages of Ecotoruism. (1999-2005). Retrieved from https://www.trails.com/facts_26212_disadvantages-ofecotourism.html

[9] EarthCheck. (2015). Products and Services. Retrieved from http://earthcheck.org/?page_id=104 \& http://earthcheck.org/products-services/

[10] Ecolabel Index. (2015). Sustainable Tourism Education Program (STEP). Retrieved from http://www.ecolabelindex.com/ecolabel/sustainable-traveleco-certification-program

[11] El-Haggar, S. (2007). Sustainable Industrial Design and Waste Management, Cradle-to-Cradle for sustainable development. Elsevier Academic Press.

[12] Fennell, D. A. (1999). Ecotourism: An Introduction. London, GBR: Routledge,. ProQuest Ebrary.

[13] G. Eileen, L. Kristin, M. Seleni and S. Kaddu, "Linking Tourism, Communities and Conservation: A Tourism Assessment Process. (2005). Retrieved from http://rmportal.net/library/content/Green_Markets_\%20Con servation_Financing_and_Socially_Responsive_Corporate_ Policies_and_Practices/nrm_eg_gree-tourismfolder/linking-communities-tourism-and-conservation-atourism-assessment-process

[14] HVS SUSTAINABILITY. (2015). ECOTEL CERTIFICATION. Retrieved from http://www.ecotelhotels.com/brochure.pdf

[15] Industrial Ecology. (2015). Retrieved from https://en.wikipedia.org/?title=Industrial_ecology

[16] Kiper. (2013). Role of Ecotourism in Sustainable Development. Retrieved from http://cdn.intechopen.com/pdfs-wm/45414.pdf

[17] Klintman. (2012). Issues of scale in te global accreditation of sustainable tourism schemes: towards harmonized reembeddedness? Sustainability: Science, Practice, \& Policy, 8(1). Retrieved from http://sspp.proquest.com/static_content/vol8iss1/1008040.klintman.pdf

[18] Miller, G. K. (2010). Public Understanding of Sustainable Tourism. Annals of Tourism Research, Elsevier Ltd, 627645. Retrieved March 15, 2015

[19] Miller, G. T.-W. (2005). Monitoring for a Sustainable Tourism Transition.

[20] Mohonk Agreement: Proposal for an International Certification Program for Sustainable Tourism and Ecotourism. (2015).

[21] Moving beyond "Ecotourism" and "Responsible Tourism" to E3 Travel Programs. (n.d.). Retrieved from http://www.ibike.org/encouragement/travel/e3.htm

[22] National-Geographic. (2008-2010). About Geotourism. National Geographic Mission Programs, Center for
Sustainable Destinations. Retrieved from

http://travel.nationalgeographic.com/travel/sustainable/pdf/ about-geotourism.pdf

[23] Rosalyn McKeown- Portland State. Education for Sustainable Development: The Oregon Context. (n.d.).

[24] Sproule,Ecotourism Questioned: Case Studies from Belize. (1996, July).

[25] Stratford, Benefits of Ecotourism. (2015). Benefits of Ecotourism. Retrieved from http://greenliving.lovetoknow.com/Benefits_of_Ecotourism

[26] Sustainable Tourism. (2014). -Eco Tourism Certification. Retrieved from http://www.sustainabletourism.net/sustainabletourism/sustainable-tourism-resource/eco-tourismcertification/

[27] Sustainable Tourism. (2014). Sustaining TourismSustainable Tourism Definitions. Retrieved June 25, 2015, from http://www.sustainabletourism.net/sustainabletourism/definitions/

[28] The International Ecotourism Society. (2013). Retrieved from www.ecotourism.org

[29] Tomomi, Ecotourism in Bali: Backgrounds, Present Conditions and Challenges. (2015).

[30] Tourism Development. (2015). Outline of Advantages and Disadvantages. Retrieved from http://www.ibike.org/encouragement/travel/tourism.htm

[31] United Nations Environment Programme. (2015). Ecotourism as a Sustainable Development Concept. Retrieved from http://www.uneptie.org/shared/publications/cdrom/webx01 39xpa/about/iye.htm

[32] UNWTO Tourism Highlights. (2013). Retrieved from http://dtxtghgw60xqpw.cloudfront.net/sites/all/files/pdf/un wto_highlights13_en_lr_0.pdf .

[33] Wood, M. E. (2002). Ecotourism: Principles, Practices \& Policies for Sustainability. Retrieved from http://www.pnuma.org/eficienciarecursos/documentos/Ecot ourism1.pdf

[34] World Tourism Organisation. (2003). Recommendation to governments for supporting and/or establising national certification systems for sustainble tourism. Retrieved from http://sdt.unwto.org/sites/all/files/docpdf/certification-govrecomm.pdf

[35] World Travel and Tourism Council. (2015). Economic Impact of Travel and Tourism. (T. A. Tourism, Ed.) Retrieved from World Travel and Tourism Council: http://www.wttc.org//media/files/reports/economic\%20impact\%20research/eco nomic\%20impact\%202015\%20summary_web.pdf 